\title{
REDEFINITION OF THE GENUS ASENSILLA RACK (ACARI: HETEROSTIGMATA: PYGMEPHORIDAE) WITH REDESCRIPTION OF A. PRASSEI
}

\section{Alexander A. Khaustov ${ }^{1^{*}}$, Sultan Çobanoglu² and Cihan Cilbircioğlu ${ }^{3}$}

\author{
${ }^{1}$ Tyumen State University, Tyumen, Russia \\ ${ }^{2}$ University of Ankara, Plant Protection Department, Ankara, Turkey \\ ${ }^{3}$ University of Kastamonu, Organic Agriculture Department, Turkey \\ *corresponding author; e-mail: alkhaustov@mail.ru
}

\begin{abstract}
The genus Asensilla Rack, 1974 and its type species A. prassei Rack, 1974 (Acari: Pygmephoridae) are redefined and redescribed, respectively, based on materials from Turkey. The genus Asensilla has been recorded for the first time in Asia. In addition, the taxonomic position of the genus Asensilla is discussed.
\end{abstract}

KEY WORDS: Systematics, Pygmephoroidea, Turkey, first record.

DOI: $10.21684 / 0132-8077-2017-25-2-129-134$

\section{INTRODUCTION}

The cosmopolitan family Pygmephoridae is the second largest in the superfamily Pygmephoroidea and includes 31 genera and more than 300 species (Khaustov et al. 2017). Probably all pygmephorid mites are fungivorous (Kaliszewski et al. 1995).

The monotypic genus Asensilla Rack, 1974, with type species Asensilla prassei Rack, 1974, has been described from soil in Germany (Rack 1974). Since that time, the genus has never been reported from any other locality. The original description of A. prassei lacks information about its leg setation, shape of ventral plates and gnathosomal structures.

The junior author has collected a series of specimens of $A$. prassei from the garlic fields of Kastanou, Turkey. The mites were collected from the bulbs of garlic plants, which remain submerged in soil during the vegetation period. Based on this material we have redefined the genus Asensilla and redescribed $A$. prassei.

\section{MATERIAL AND METHODS}

Specimens of $A$. prasse $i$ were extracted from garlic with soil samples with the help of a Berlese funnel. Mites were mounted on slides in Hoyer's medium. The terminology of idiosoma and legs follows that of Lindquist (1986); the nomenclature of subcapitular setae and the designation of cheliceral setae follow those of Grandjean $(1944,1947)$, respectively. The systematics of Pygmephoroidea follows that of Khaustov $(2004,2008)$. All measurements are given in micrometers $(\mu \mathrm{m})$. For leg chaetotaxy, the number of solenidia is given in parentheses. Mite morphology was studied using a Carl Zeiss Axio Imager A 2 compound microscope with DIC and phase contrast objectives. Photomi- crographs were taken with an AxioCam ICc5 digital camera.

\section{RESULTS}

\section{Family Pygmephoridae Cross, 1965}

Genus Asensilla Rack, 1974

Type species: Asensilla prassei Rack, 1974, by original designation

Diagnosis. Female. Body well sclerotized, oval. Gnathosomal capsule of about equal length and width dorsally, with one pair of cheliceral setae (cha), setae chb absent; postpalpal setae ( $p p)$ present; palps prominent, with two pairs of setae $(d F e$, $d G e)$; tibial claw large; palpal solenidion well developed, accessory setigenous structure (ass) large, mushroom-like. Subcapitular setae $(m)$ present. Subcapitulum with one pair of oval pits in posterior half. Pharyngeal pumps tripartite, situated on long and thin oesophagus; pump 1 butterfly-like, smooth, far separated from pump 2, pumps 2 and 3 subequal, oval, situated close to each other. Prodorsum with three pairs of setae $\left(v_{1}, v_{2}, s c_{2}\right)$ and one pair of oval stigmata; trichobothria absent; prodorsal shield not divided. Tracheal trunks thin, long. Posterior part of prodorsal shield covering anterior part of tergite $\mathrm{C}$. Tergite $\mathrm{C}$ with two pairs of setae $\left(c_{1}, c_{2}\right)$; tergite $\mathrm{D}$ with one pair of setae $(d)$ and one pair of round cupules $i a$; tergite $\mathrm{EF}$ with two pairs of setae $(e, f)$ and one pair of round cupules $\mathrm{im}$; tergite $\mathrm{H}$ with two pairs of setae $\left(h_{1}, h_{2}\right)$ and one pair of round cupules $i h$. Coxal fields I with two pairs of setae $(1 a, 1 b)$, setae $1 b$ not modified, setae $1 c$ absent; coxal fields II with two pairs of setae $(2 a, 2 c)$; coxal fields III with three 
pairs of setae $(3 a, 3 b, 3 c)$; coxal fields IV with three pairs of setae $(4 a, 4 b, 4 c)$. Pseudanal segment with three pairs of setae $\left(p s_{1-3}\right)$. Apodemes 1 (ap1) well developed, thick, apodemes 2 (ap2) well developed, joined with well-developed prosternal apodeme (appr); appr joined with sejugal apodeme (apsej); secondary transverse apodeme (sts) present; apodemes 3 (ap3) weak, diffuse, represented by two curved separated lines; poststernal apodeme (appo) well developed, fused with long apodemes 4 (ap4). Posterior margin of posterior sternal plate entire. Anterior (ags) and posterior (pgs) genital sclerites situated close to each other. Leg I 4-segmented, with massive tibiotarsus and large tarsal claw. Unguinal setae fused to form structure opposing the tarsal claw. Tibiotarsus without pinnaculum. Seta $d$ of femur I unmodified. Seta $k$ smooth, pointed. Seta $l$ " of femur absent. Legs II-IV each with one pair of claws and elongated empodium. Claws on tarsi II and III padded, on tarsus IV simple. Genu II without seta l”. Tibia IV without solenidion. Femora III and IV divided into basi- and telofemur. Leg setation: leg I; tr $1\left(v^{\prime}\right)$, fe $3\left(d, l^{\prime}, v^{\prime \prime}\right)$, ge $3\left(l^{\prime}, l^{\prime \prime}, v^{\prime \prime}\right)$, tita 17(4) (d, l', l', $v^{\prime}$, $v^{\prime \prime}, k, t c^{\prime}, t c^{\prime \prime}, p^{\prime}, p^{\prime \prime}, f t^{\prime}, f t^{\prime \prime}, p v^{\prime}, p v^{\prime \prime}, p l^{\prime}, p l{ }^{\prime \prime}, s$, $\left.\omega_{1}, \omega_{2}, \varphi_{1}, \varphi_{2}\right)$; leg II: tr $1\left(v^{\prime}\right)$, fe $3\left(d, l^{\prime}, v^{\prime \prime}\right)$, ge 2 $\left(l^{\prime}, v^{\prime}\right)$, ti 4(1) (d, l', $\left.v^{\prime}, v^{\prime \prime}, \varphi\right)$, ta 6(1) (tc', $t c^{\prime \prime}, p l^{\prime \prime}$, $\left.p v^{\prime}, p v^{\prime \prime}, u^{\prime}, \omega\right)$; leg III: tr $1\left(v^{\prime}\right)$, fe $2\left(d, v^{\prime}\right)$, ge 2 $\left(l^{\prime}, v^{\prime}\right)$, ti 4(1) $\left(d, l^{\prime}, v^{\prime}, v^{\prime \prime}, \varphi\right)$, ta $6\left(t c^{\prime}, t c^{\prime}, p l^{\prime \prime}\right.$, $\left.p v^{\prime}, p v^{\prime \prime}, u^{\prime}\right)$; leg IV: tr $1\left(v^{\prime}\right)$, fe $2\left(d, v^{\prime}\right)$, ge $1\left(v^{\prime}\right)$, ti 4 ( $\left.d, l^{\prime}, v^{\prime}, v^{\prime \prime}\right)$, ta 6 ( $\left.p l^{\prime \prime}, t c^{\prime}, t c^{\prime \prime}, u^{\prime}, p v^{\prime}, p v^{\prime \prime}\right)$.

Male and larva unknown.

Species included. The genus Asensilla includes one species, A. prassei Rack, 1974.

Distribution and habitat. A. prassei inhabits soils in Germany (Rack 1974) and Turkey (present data). This is a new record of the genus Asensilla in Asia.
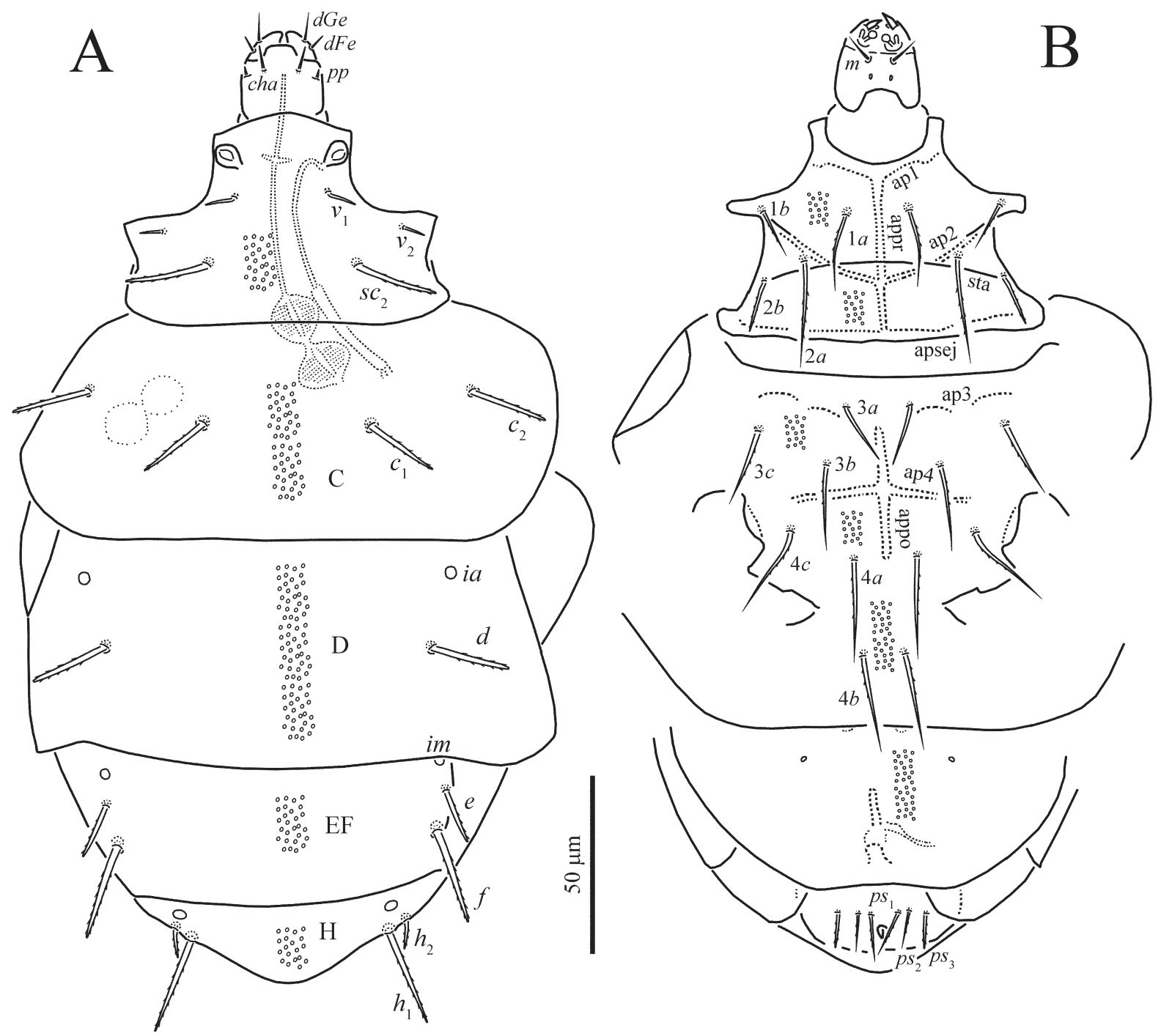

Fig. 1. Asensilla prassei Rack, 1974, female: A-dorsum of the body, B-venter of the body. Legs omitted. 


\section{Asensilla prassei Rack, 1974}

(Figs. 1-4)

Redescription. Female (Figs. 1-4). Length of idiosoma 230-250, width 145-155.

Gnathosoma. Length of gnathosoma 21-23, width 23-24. Dorsal median apodeme absent. All gnathosomal setae smooth. Setae $c h a 7-8, d F e$ and $p p$ needle-like. Setae $d G e$ pointed, distinctly longer than $d F e$. Postpalpal setae situated laterally to setae cha. Subcapitular setae $m 6$ pointed.

Idiosomal dorsum (Figs. 1A, 4A-E). All dorsal shields with numerous and rather large dimples (Figs. 4C, D). All dorsal setae blunt-ended. Setae $v_{1}$ and $v_{2}$ smooth, other dorsal setae weakly barbed.
Cupules $i a$ on tergite $\mathrm{D}$, im on tergite $\mathrm{EF}$, and $i$ on tergite $\mathrm{H}$ large, round. Setae $e$ situated distinctly anteriorly to $f$. Prodorsum with one pair of oval subcuticular areas (Fig. 4E), located between setae $s c_{2}$; tergite $\mathrm{C}$ with two pairs of oval subcuticular areas (Fig. 4E) located between setae $c_{1}$ and $c_{2}$. Lengths of dorsal setae: $v_{1} 8-10, v_{2} 6-7, s c_{2} 23-25$, $c_{1}$ 20-24, c 22-24, d 22-23, e 15-17, f27-30, $h_{1}$ 28-31, $h_{2}$ 10-11. Distances between setae: $v_{1}-v_{1}$ 25-26, v $v_{2}-v_{2} 62-67, s c_{2}-s c_{2} 38-42, c_{1}-c_{1} 43-47$, $c_{1}-c_{2} 30-34, d-d$ 90-94, e-f 11-11, $f-f$ 88-92, $h_{1}-h_{1} 52-57, h_{1}-h_{2} 6-7$.

Idiosomal venter (Figs. $1 \mathrm{~B}, 4 \mathrm{~B}, \mathrm{~F}$ ). Ventral plates with numerous rather large dimples (Fig. $4 \mathrm{~F})$. Setae $3 a$ smooth, other ventral setae weakly

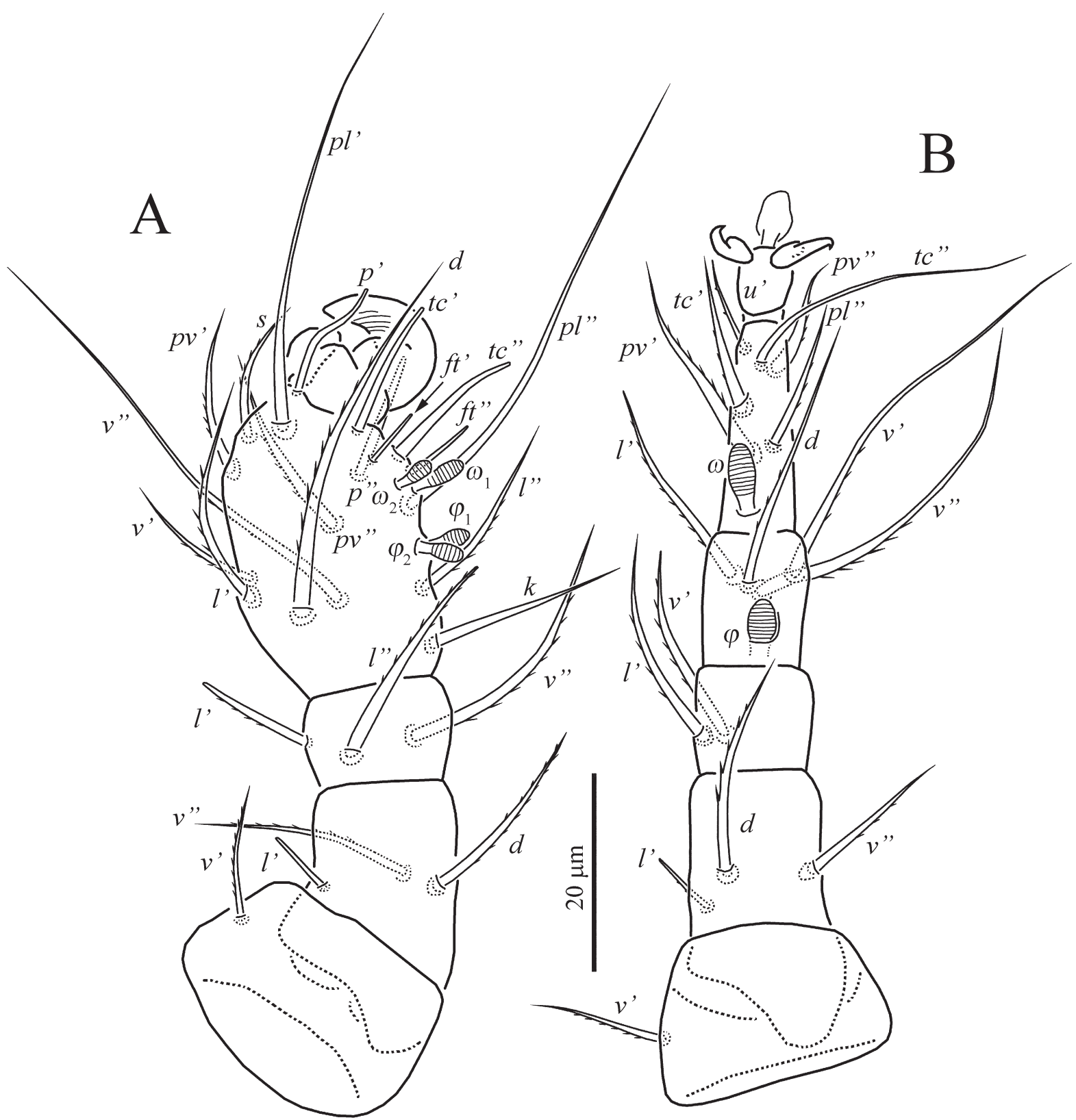

Fig. 2. Asensilla prassei Rack, 1974, female: A—right leg I in dorsal view, B—right leg II in dorsal view. 


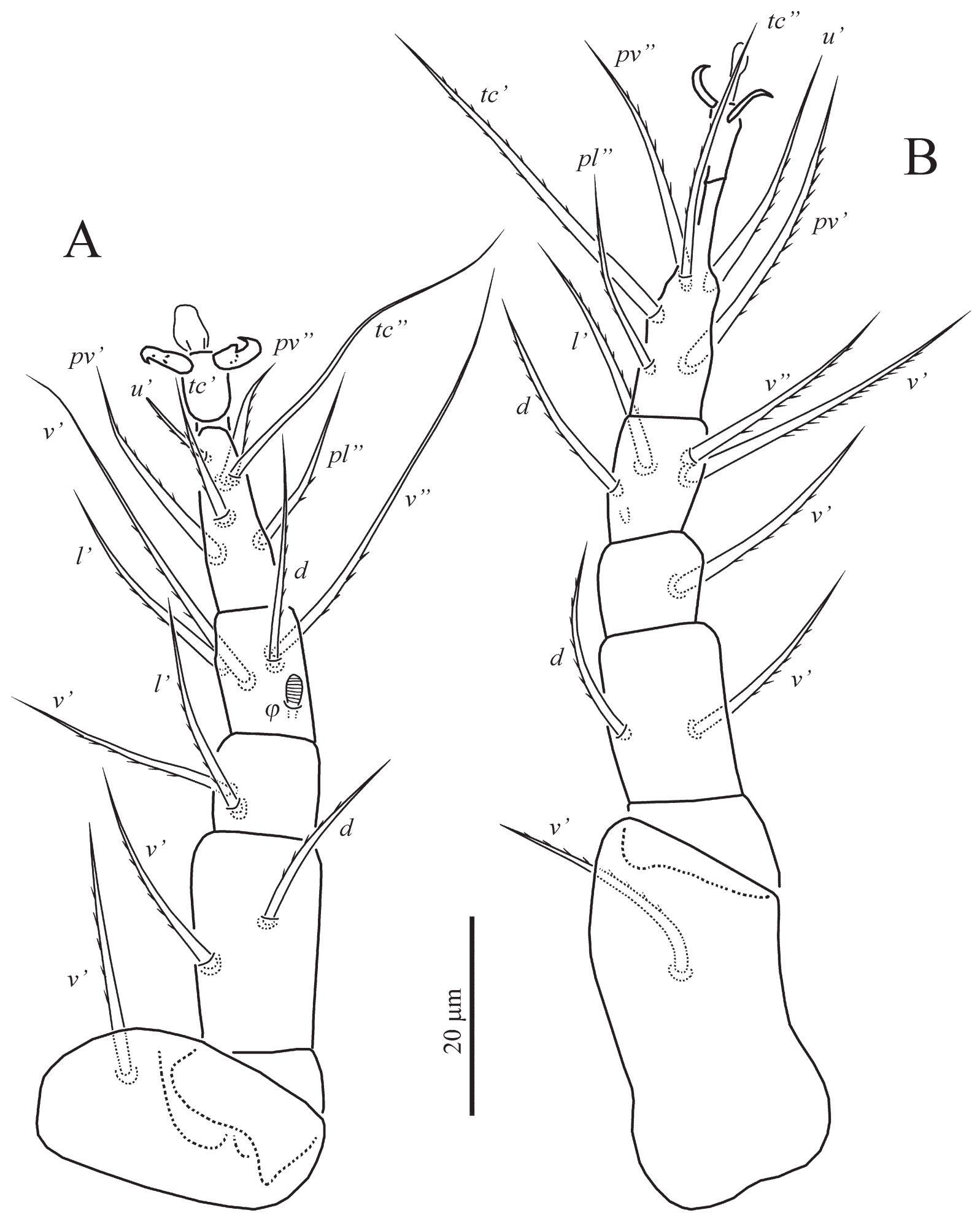

Fig. 3. Asensilla prassei Rack, 1974, female: A—right leg III in dorsal view, B—right leg IV in dorsal view.

barbed. Setae $2 c, 3 a$ and $p s_{3}$ blunt-ended, other ventral setae pointed. Lengths of ventral setae: $1 a$ 22-26, 1b 14-15, 2a 29-31, 2c 15-16, 3a 16-17, $3 b 23-26,3 c 25-27,4 a 28-32,4 b 28-30,4 c 27-29$, $p s_{1} 13-15, p s_{2} 10-11, p s_{3} 10-11$.

Legs (Figs. 2, 3). Leg I (Fig. 2A). Tarsal claw with blunt tip. Inner surface of tarsal claw weakly striated. Lengths of solenidia $\omega_{1} 6, \omega_{2} 5, \varphi_{1} 5, \varphi_{2} 5$; all solenidia clavate. Seta $l$ ' of femur, $l$ ' and $l$ '" of genu blunt-ended, other leg setae (except eupathidia) pointed. Setae $l$ ' of femur, $k$ and $(p l)$ of tibiotarsus smooth, other setae (except eupathidia) weakly barbed. Leg II (Fig. 2B). Solenidion $\omega 7-8$ and solenidion $\varphi 6$ weakly clavate. Setae $l$ ' of fe- 


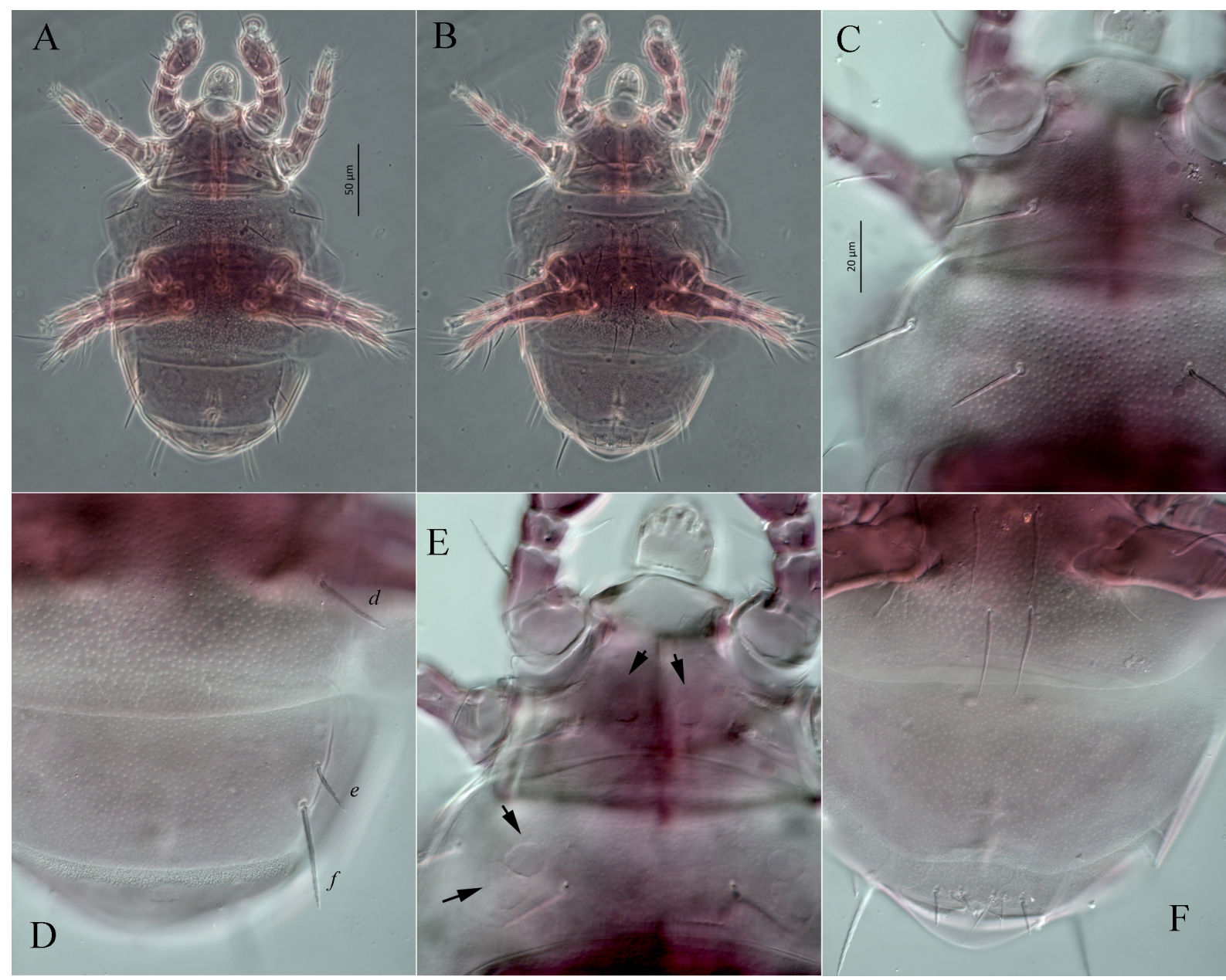

Fig. 4. Phase contrast (A, B) and DIC micrographs (C-F) of Asensilla prassei Rack, 1974, female: A-general view dorsally, B - general view ventrally, $\mathrm{C}$ - prodorsum and tergite $\mathrm{C}, \mathrm{D}$ - tergites D and EF, E- oval subcuticular areas (arrowed), F-opisthosoma in ventral view.

mur, $v$ 'of genu, $l$ ' of tibia, and $u$ ' of tarsus weakly blunt-ended, other setae pointed. Seta $t c$ " of tarsus smooth, other setae weakly barbed. Leg III (Fig. 3A). Solenidion $\varphi 5$ weakly clavate. Seta $u$ ' of tarsus weakly blunt-ended, other setae pointed. Seta $t c$ " of tarsus smooth, other setae weakly barbed. Leg IV (Fig. 3B). All setae pointed and weakly barbed. Solenidion $\varphi$ absent, but internal invagination visible on its typical insertion point.

Material examined. Five females, 09.07.2015 (code No. B-207) Taşköprü-Yukarı Ermece Village; one female, 23.06.2015 (code No. B-228) Hanönü Kuyluş Village, from Garlic Bulbs, from garlic growing fields, Kastamonu, Turkey.

Deposition of material. The voucher specimens of species redescribed here are deposited in the mite collection of the Department of Plant Protection, University of Ankara, Turkey (five specimen) and Tyumen State University, Russia (one specimen).

Remarks. The redescription of $A$. prassei is based on the material from Turkey. The Turkish specimens agree with original description of this species in all details and undoubtedly conspecific with the specimens from Germany.

\section{DISCUSSION}

The genus Asensilla is similar to the genus Dudichiana Mahunka, 1970 in the absence of setae $1 c$ and the presence of unmodified seta $d$ of femur I. However, in Dudichiana trichobothria are well developed (they are absent in Asensilla). Unfortunately, since the leg setation has not been described for Dudichiana, we were not able to compare it to that of Asensilla. The leg setation of the genus Asensillar is most similar to that of the genus Pseudopygmephorellus Khaustov, 2008 (setae v' of genu I and $l$ "' of genu II absent), however, in Asensilla seta $l$ " of femur I is absent (present in Pseudopygmephorellus) and seta $d$ of femur I is not modified (hook-like in Pseudopygmephorellus). The complete absence of trichobothria in Pygmephoridae is known only in the genus Micropygme- 
phorus Khaustov, Hugo-Coetzee and Ermilov, 2017. Khaustov et al. (2017) suggested that Asensilla and Micropygmephorus are very similar to each other by the absence of setae on trochanters I-III. In fact, the present study has revealed that setae on trochanters I-III are present in Asensilla. Most probably, the reduction of trichobothria in Asensilla and Micropygmephorus is a result of homoplasy.

\section{ACKNOWLEDGEMENTS}

This article is part of the $\mathrm{PhD}$ thesis of C. C1lbırcioğlu, which was financially supported by the Turkish Council of Research (Tubitak Tovag grant No. 114-O4-62). We are grateful to Esra Daştan for helping with the preparation of the slides.

\section{REFERENCES}

Grandjean, F. 1944. Observations sur les Acariens de la famille des Stigmaeidae. Archives des Sciences Physiques et Naturelles, 26: 103-131.

Grandjean, F. 1947. L'origine pileuse des mors et la chaetotaxie de la mandibule chez les Acariens actinochitineux. Comptes rendus des Séances de l'Academie des Sciences, 224: 1251-1254.

Kaliszewski, M., Athias-Binche, F. and Lindquist, E.E. 1995. Parasitism and parasitoidism in Tarsone- mina (Acari: Heterostigmata) and evolutionary considerations. Advances in Parasitology, 35: 335-367.

Khaustov, A.A. 2004. Mites of the family Neopygmephoridae Cross, 1965 stat. n. and their position in Heterostigmata. In: Yu.S. Balashov (Ed.). VIII Russian Acarological Conference, St.-Petersburg. Zoological Institute of RAS, St.-Petersburg, 137. [In Russian]

Khaustov, A.A. 2008. Mites of the family Scutacaridae of Eastern Palaearctic. Akademperiodyka, Kiev, $291 \mathrm{pp}$.

Khaustov, A.A., Hugo-Coetzee, E.A. and Ermilov S.G. 2017. A new genus and two new species of Pygmephoridae (Acari: Heterostigmata) associated with Trinervitermes trinervoides (Isoptera: Termitidae) from South Africa. Zootaxa, 4258 (5): 462-476.

Lindquist, E.E. 1986. The world genera of Tarsonemidae (Acari: Heterostigmata): a morphological, phylogenetic, and systematic revision, with a reclassification of family-group taxa in the Heterostigmata. Memoirs of the Entomological Society of Canada, 118: 1-517.

Rack, G. 1974. Neue und bekannte Milbenarten der Überfamilie Pygmephoroidea aus dem Saalkreis bei Halle (Acarina, Tarsonemida). Entomologische Mitteilungen aus dem Zoologischen Museum Hamburg, 4: 499-521. 